\title{
De nuevo sobre el derecho de reintegro de los gastos de electrificación en los procesos de urbanización. Comentarios a las Sentencias de TS de 25 noviembre de 2002 (recursos 154/2001 y 157/2001
}

\author{
Vicente Ortells Rubert \\ Profesor Derecho Administrativo. Universitat Jaume I \\ Joaquín Llidó Silvestre \\ Secretario de Administración Local
}

\begin{abstract}
Sumario: 1. INTRODUCCIÓN. 2. LA (¿DEFINITIVA?) POSICIÓN DEL TRIBUNAL SUPREMO ANTE EL DERECHO DE REINTEGRO. 3. LAS CONSECUENCIAS QUE EL TRIBUNAL SUPREMO EXTRAE DEL NUEVO RÉGIMEN JURÍDICO DE LAS OBLIGACIONES URBANIZADORAS DE LOS PROPIETARIOS DEL SUELO. 3.1. Sobre la supuesta modificación de «importancia» de la legislación urbanística a través de la LRSV. 3.2. Sobre la pretendida distinción entre lod deberes de los propietarios en la LRSV y el TRLS 76. 3.3. Sobre si el derecho de reintegro es materia «urbanismo». 3.4. El título competencial invacado por el TS para la eliminación del derecho de reintegro. 4. SOBRE LO QUE EL TRIBUNAL SUPREMO SILENCIA DEL RÉGIMEN CONTENIDO EN EL RD. 5. SOBRE EL TRATAMIENTO QUE EL TRIBUNAL SUPREMO HACE PRINCIPIO DE INTERDICCIÓN DEL ENRIQUECIMIENTO INJUSTO.
\end{abstract}

\section{INTRODUCCIÓN}

Desde hace unos años se ha venido manifestando una preocupación doctrinal $^{1}$ y jurisprudencial acerca del modo en que se pudiera ensamblar el régimen jurídico del sector eléctrico y el de las obligaciones urbanísticas de la propiedad inmobiliaria, en el concreto punto de la ejecución de infraestructuras e instalaciones eléctricas para atender a las nuevas demandas de suministros y la urbanización de los terrenos para convertirlos en solares.

\footnotetext{
${ }^{1}$ Entre la doctrina más reciente: «Los derechos de acometida en los servicios públicos de suministro de agua potable y energía eléctrica», de J.V. BELENGUER MULA, en REALA, n. ${ }^{\circ} 273$, enero-abril de 1997; «El derecho de los propietarios al reintegro de los gastos de instalación de las redes de suministro de energía eléctrica», de B. COLOM PASTOR, en REALA n.. ${ }^{\circ} 278$, septiembre-diciembre de 1998; «El derecho de reintegro de los gastos de urbanización contra las compañías suministradoras de energía eléctrica», de J. CATALAN SENDER, en $R D U$ y $M A$, n. $^{\circ} 165$, de noviembre de 1998; «El derecho de reintegro de los gastos de electrificación en los procesos de urbanización. Los efectos del RD 19555/2000, de 1 de diciembre», de V. Ortells RuberT y J. Llido Silvestre, en REALA n. ${ }^{\circ}$ 286-287, de mayo-diciembre de 2001; «Jurisprudencia del TS sobre extensión de redes», de Joaquín M ${ }^{a}$ Nebreda Pérez, en El Consultor de los Ayuntamientos, n. ${ }^{\circ}$ 4, de 28 de febrero de 2003; «El nuevo régimen de imputación de los costes de electrificación», de Ernesto CEBRIAN DOMÍNGUEZ, en repertorio de jurisprudencia Aranzadi.
} 
La problemática a la que se asiste, con arreglo a la vigente regulación sectorial, puede resumirse del siguiente modo:

a) Por un lado la legislación eléctrica (arts 9.1.g, 41.1.c y 45.1.a) de la Ley 54/1997, de 27 de noviembre, del Sector Eléctrico, LSE) impone a las compañías distribuidoras la obligación de «proceder a la ampliación de las instalaciones de distribución cuando así sea necesario para atender nuevas demandas de suministro eléctrico» $\mathrm{y}$ "atender en condiciones de igualdad las demandas de nuevos suministros eléctricos».

b) Por otro lado, la legislación estatal sobre derechos y obligaciones urbanísticas de la propiedad inmobiliaria (ahora, en particular, arts. 14.1.; 14.2.e y 18.3 y 6 de la Ley estatal 6/1998, de 13 de abril, sobre Régimen del Suelo y Valoraciones, LRSV) impone a los propietarios de los terrenos el deber de dotarlos del servicio, entre otros, de suministro eléctrico.

La provisión de las infraestructuras eléctricas, en una práctica basada en la lógica de la razonable realización integral, total y de una sola vez de las obras de urbanización, se efectúa en unidad de acción con todas las demás operaciones de transformación del suelo y de dotación de servicios e infraestructuras para su aprovechamiento urbanístico, por lo que la dual localización subjetiva de la obligación de provisión de infraestructuras eléctricas se resuelve en la práctica cotidiana con el cumplimiento de su obligación (consistente en costear y/o ejecutar las instalaciones) por los propietarios de los terrenos quienes, a su terminación, las entregan (directamente o por medio de la Administración urbanística) a las compañías distribuidoras, únicas que pueden (y deben) prestar el servicio de suministro eléctrico (art. 44.1. de la LSE). Que esta práctica, además, sea acorde con el derecho vigente, es indudable. En efecto, el art. 15 de la LRSV consagra para los propietarios del suelo urbanizable, además del deber que se ha citado, el derecho a su urbanización (o transformación, en la terminología de la Ley) y lo mismo viene a decir en el art. 13 de la LRSV respecto de los propietarios del suelo urbano.

Hasta ahora también se ha venido admitiendo ${ }^{2}$ que el instrumento de que disponían los propietarios de los terrenos para resarcirse de los costes

\footnotetext{
2 Por todas, STS de 27.11.95, RA 8870, en la que se dice: «...después de señalar que entre los gastos de urbanización que deben ser sufragados por los propietarios afectados se encuentran los de suministro de agua y de energía eléctrica, se añada sin perjuicio del derecho a reintegrarse de los gastos de instalación de las redes de suministro de agua y energía eléctrica con cargo a las empresas que presten los servicios, salvo la parte que deban contribuir los usuarios según la reglamen-
} 
de dotación de infraestructuras eléctricas que entregan a las compañías distribuidoras y que aquéllas también venían obligadas a ejecutar conforme a la LSE, es el derecho de reintegro previsto en la legislación urbanística, en un principio estatal y ahora, mayoritariamente, autonómica, en congruencia con la lógica del sistema que sitúa en este ámbito la regulación de la acción urbanizadora (en nuestro caso el de la provisión material de infraestructuras y pago de las mismas) ${ }^{3}$.

La duda acerca de si ese esquema era todavía admisible surgió con la promulgación del Real Decreto 1955/2000, de 1 de diciembre, por el que se regulan las actividades de transporte, distribución, comercialización, suministro y procedimientos de autorización de instalaciones de energía eléctrica (en adelante RD), dictado en desarrollo de la LSE, a la vista del cual, en relación con la pervivencia del derecho de reintegro, se podían sostener dos posturas: Entender que el RD citado en nada había afectado a este derecho o, por el contrario, que lo había dejado sin efecto o vacío de contenido ${ }^{4}$. Una inicial aproximación al asunto permitía defender la primera de las posiciones que, además de contar con el respaldo de unas prontas resoluciones jurisdiccionales siquiera fuera con el carácter de «obiter dicta» por no ser aplicable, por razones temporales, el RD a los asuntos controvertidos en sede judicial ${ }^{5}$, se fundaba, en síntesis, en lo siguiente:

a) El derecho de reintegro ha estado regulado, históricamente, en sede de la materia «urbanismo» (Texto Refundido de la Ley del Suelo de 1976, art. 122.1.a); Texto Refundido de la Ley del Suelo de 1992, art. 155.1.a); Reglamento de Gestión Urbanística de 1978, art. 59.2;

tación de aquéllos, y ello porque dentro de la unidad de ejecución en cuyo interés se ejecuta la urbanización... habrá dotaciones que no sólo benefician a tales propietarios, sino a toda la colectivi$d a d » ;$ y la de 22 de diciembre de 2000 (RA 326 de 2001), en la que se dice lo siguiente: «...En efecto los costes de urbanización deben ser sufragados sin duda alguna por los propietarios de los terrenos afectados, sin perjuicio de que, en un momento ulterior y de acuerdo con certificaciones de los costes de instalación de la red de energía eléctrica que se expidan, puedan estos eventualmente resarcirse de la empresa concesionaria que preste el servicio de aquella parte que, según la reglamentación correspondiente, no tuviera que correr a cargo de los usuarios del servicio».

${ }^{3}$ Ver arts. 122.1.a) del Texto Refundido de la Ley del Suelo de 1976; 59.2 del Reglamento de Gestión Urbanística y ahora legislación urbanística autonómica en sentido muy similar al de las normas estatales que se acaban de citar.

${ }^{4}$ Sosteniendo las dos tesis se pueden encontrar opiniones en los últimos trabajos publicados y citados en la nota 1 .

${ }^{5}$ En el trabajo citado de V. OrTElls Rubert y J. Llido Silvestre se hace referencia a las Sentencias del Juzgado de lo Contencioso-Administrativo n. ${ }^{\circ} 1$ de Castellón, de 8 de marzo y 12 de abril de 2001. 
y ahora legislación urbanística autonómica) que, por imperativo el art. 148.1.3 a es competencia de las Comunidades Autónomas y, en cambio, el RD se dicta, en su parte general referida a las obligaciones de extensión de las redes eléctricas, al amparo de los títulos competenciales que al Estado reconoce el art. 149.1.13 (bases y coordinación de la planificación general de la actividad económica) y 149.1.25 (bases del régimen minero y energético) de la Constitución, de modo que el Estado, al dictar el RD no invoca -no puede hacerlo- el título competencial «urbanismo» bajo el que tradicionalmente se había regulado el derecho de reintegro. Y, lo que es más significativo por lo que luego se verá: El Estado tampoco invoca, para dictar el RD, el título del art. 149.1.1 ${ }^{a} \mathrm{CE}$ (regulación de las condiciones básicas que garanticen la igualdad de todos los españoles en el ejercicio de los derechos y en el cumplimiento de las obligaciones constitucionales) ${ }^{6}$.

b) En cualquier caso, pervive el principio de interdicción del enriquecimiento injusto que, de no entender vigente el derecho de reintegro, permitiría fundar las pretensiones de restitución de los costes de provisión de unas infraestructuras a favor de los propietarios que los soportaron y que han de entregar a las compañías privadas del ramo para que hagan su propio negocio.

\section{LA (¿DEFINITIVA?) POSICIÓN DEL TRIBUNAL SUPREMO ANTE EL DERECHO DE REINTEGRO}

El TS ha resuelto la duda que suscitó el RD acerca de la pervivencia del derecho de reintegro, pues en sus dos sentencias de 25 de noviembre de 2002 , dictada una en recurso $154 / 2001^{7}$ y otra en recurso $157 / 2001^{8}$, afirma que el derecho de reintegro ha sido profundamente alterado tanto por el nuevo régimen jurídico del sector eléctrico como por el que regula el

\footnotetext{
${ }^{6}$ Es cierto que ese no es un modo incorrecto de proceder, pues es doctrina del TC (S.164/2001, de 11 de julio) la de que «...debemos distinguir con claridad...entre el deber estatal de identificar formal y expresamente sus normas básicas... y la inexistente obligación del legislador de invocar expresamente el título competencial que ampara sus leyes...no existiendo un deber estatal de nominar sus títulos competenciales...» (FJ 56).

${ }^{7}$ Recurso contencioso-administrativo interpuesto por la Asociación de Promotores Constructores de España.

${ }^{8}$ Recurso contencioso-administrativo interpuesto por la Asociación Española de Promotores Públicos de Vivienda y Suelo (AVS). Tanto éste como el recurso citado en la nota anterior tienen por objeto el RD que aquí se comenta.
} 
contenido urbanístico de la propiedad inmobiliaria, a los que se ha hecho referencia en la introducción, hasta el punto de que en la sentencia dictada en el segundo de tales recursos afirma (fundamento jurídico cuarto) que «...el artículo 122.1.a) de la Ley del Suelo de 9 de abril de 1976 -único del derecho estatal con rango legal que regula el derecho de reintegro- ha sido derogado».

Es de entender que se pretenda sostener una posición intelectual que postule unificar para toda España, ante la regulación por el derecho urbanístico (autonómico) del derecho de reintegro de forma eventualmente dispersa y opuesta, el régimen de obligaciones de las compañías eléctricas o, dicho de otro modo y visto desde otra óptica, el régimen de obligaciones urbanísticas de la propiedad inmobiliaria.

Esa uniformidad es a la que parece tender la doctrina del Tribunal Supremo fijada en las dos sentencias que se comentan que, en la última que se ha citado no sólo declara expresamente derogada la norma estatal que regula el derecho de reintegro, sino que, cuando se refiere a las normas autonómicas urbanísticas que ahora lo regulan y que el Tribunal no puede concluir derogadas, entiende que las previsiones del RD no contradicen el derecho de reintegro de sede legal autonómica (p.ej. fundamento de derecho quinto.I.C de la sentencia dictada en recurso 157/2001) que pervive pero indicando (fundamento jurídico II de la misma sentencia) que «cuando en ellas se va más allá de una previsión genérica sobre lo gastos de urbanización, se hace remisión a la legislación especifica correspondiente; en este caso, a la del sector eléctrico...» y añade que «...no significa que queden sin contenido las normas autonómicas que afirman la existencia de un derecho de los propietarios a reintegrarse de estos gastos. En efecto, sucede que, por debajo de los umbrales de potencia a los que se refiere el artículo 45.1, son directamente las distribuidoras las que deben asumirlos. Además, las reglas autonómicas invocadas por la actora no sólo se refieren a las instalaciones para el suministro de energía eléctrica. De ahi que, tratándose de otros suministros pueda caber una solución diferente...», con lo que fija el reducto en el que ha quedado definitivamente confinado el antiguo derecho de reintegro.

Para alcanzar esas conclusiones, que son las que sirven al propósito unificador o igualador citado más arriba, es necesario el proceso intelectual de extraer el derecho de reintegro de la materia «urbanismo» (autonómica), en la que tradicionalmente ha tenido su sede, y residenciarlo en alguno de los títulos competenciales estatales que, desde el punto de vista material, puedan acogerlo. 
Eso es lo que hace el Tribunal (fundamento jurídico quinto.II de la sentencia dictada en recurso 157/2001) que, en primer lugar, para llegar a concluir que la competencia del Estado para abordar este asunto deriva del art. 149.1.25 de la Constitución, sobre las bases del régimen minero y energético -que es uno de los invocados por el RD en fundamento la habilitación estatal para su promulgación y para conferirle carácter básico, Disposición Final Primera.1-, parte de la base de que la regulación que del derecho hacen las normas urbanísticas autonómicas «...cuando en ellas se va más allá de una previsión genérica sobre los gastos de urbanización, se hace remisión a la legislación específica correspondiente, en este caso, a la del sector eléctrico.» Establecida esa conclusión, el Tribunal refuerza su posición, afirmando que, además, la regulación del RD, «enlaza con las previsiones de la Ley 6/1998, aplicables en toda España» $\mathrm{o}$, en términos más expresivos, en respuesta a las quejas de las demandantes en el sentido de que el RD carece de cobertura legal, el Tribunal indica que justamente los arts. 14.2.e) y 18.3 de la LRSV le otorgan «cobertura legislativa» (fundamento de derecho séptimo. 2 de la sentencia dictada en recurso 154/2001) o, dicho de otro modo, «el desarrollo reglamentario se ha hecho en consonancia con la Ley 6/1998....de tal forma que, aún para el hipotético caso de que se entendiera que ha habido una extralimitación respecto de la Ley 54/1998, la Ley posterior (la LRSV) concede respaldo suficiente para la regulación que sobre acometidas ha hecho el Reglamento» (fundamento jurídico quinto.II de la sentencia dictada en recurso 157/2001).

\section{LAS CONSECUENCIAS QUE EL TRIBUNAL SUPREMO EXTRAE DEL NUEVO RÉGIMEN JURÍDICO DE LAS OBLIGACIONES URBANIZADORAS DE LOS PROPIETARIOS DEL SUELO}

Ya se ha dicho que uno de los pilares de la argumentación del Tribunal Supremo es que la LRSV «se pronuncia sobre los deberes de los propietarios en forma diferente, en lo que ahora nos importa, a cómo lo hacía la legislación anterior» (fundamento jurídico sexto de la sentencia dictada en recurso 154/2001). Compararemos, por tanto, si efectivamente se ha producido tal cambio, estableciendo, a tal fin, la oportuna diferenciación entre lo que disponía el Texto Refundido de la Ley del Suelo de 1976 y lo que ahora es contenido de la LRSV que son precisamente las normas que confronta el Tribunal Supremo. 


\subsection{Sobre la supuesta modificación de «importancia» de la legislación urbanística a través de la LRSV}

Pero antes de efectuar la comparación conviene anotar que no parece sostenible que el Tribunal, si tiene en cuenta el reparto constitucional de competencias, diga que «se han experimentado modificaciones de importancia en la legislación urbanística, especialmente como consecuencia de la Ley 6/1998, sobre régimen del suelo valoraciones» (fundamento jurídico sexto de la sentencia dictada en el recurso 154/2001 y en el mismo sentido el fundamento jurídico cuarto de la sentencia dictada en el recurso 157/2001), pues es evidente que la Ley 6/1998 no es una ley urbanística porque, emanando del Estado, no lo puede ser por falta de habilitación competencial para dictarla. Lo reconoce la propia exposición de motivos de la LRSV cuando dice que «El legislador estatal, que carece constitucionalmente de competencias en materia de urbanismo y de ordenación del territorio, en sentido propio...sólo puede aportar una solución parcial...» por lo que «...su obra reclama una continuación por parte de los legisladores de las diferentes Comunidades Autónomas...», en concordancia con lo cual el texto legal es reiterativo en sus remisiones a la legislación urbanística (p.ej. arts. 14.2.c ó 18.4). Por eso, el párrafo de la exposición de motivos de la LRSV que transcribe el Tribunal Supremo para fundar su tesis de que el régimen urbanístico del suelo ha cambiado con la LRSV (el promotor debe asegurar «la ejecución, a su costa, de las infraestructuras de conexión con los sistemas generales que la naturaleza e intensidad de dichas actuaciones demande en cada caso e, incluso, el reforzamiento y mejora de dichos sistemas generales cuanto ello resulte necesario, exigencias mínimas éstas que por su carácter de tales contribuyen a delimitar las condiciones básicas del ejercicio del derecho de propiedad») se ha de enmarcar en el contexto de la propia exposición de motivos que, decidida y expresamente, llama a la colaboración autonómica.

De modo que la LRSV no ha podido introducir modificaciones, $\mathrm{y}$ menos que éstas hayan sido «de importancia», en la legislación urbanística y menos todavía puede, como con rotundidad afirma el Tribunal Supremo según ya se ha dicho, haber derogado «...el artículo 122.1.a) de la Ley del Suelo de 9 de abril de 1976» (fundamento jurídico cuatro de la sentencia dictada en el recurso 157/2001).

En efecto, la STC 61/1997 citada (FJ 12.d) enjuicia la adecuación a la Constitución de la Disposición Derogatoria Unica del Texto Refundido de la Ley del Suelo de 1992, que había derogado el precedente derecho urbanístico estatal de rango legal y partiendo de la base de que, tras asumir todas las Comunidades Autónomas la competencia exclusiva en materia 
de urbanismo y evidenciar, consecuencia de ello, que el Estado ya no puede dictar normas supletorias en tal materia al carecer de título competencial para ello, y tras añadir que la cláusula de supletoriedad del derecho estatal (art. 149.3 CE) no es un título atributivo de competencia, concluye el TC que el Estado carece de título que le permita «derogar el que era su propio derecho, en este caso sobre urbanismo, pero que ya ha dejado de serlo o, más exactamente, que no se encuentra a su disposición, ya sea para alterarlo...o para derogarlo. De otro modo, si el legislador estatal suprimiese, mediante su derogación, el derecho sobre una materia cuya competencia ya no es suya, sino de las Comunidades Autónomas, vendría a quebrantar una de las finalidades básicas de la cláusula de supletoriedad, cual es la de que, con la constitución de los órganos de poder de las Comunidad Autónomas, y su correspondiente asunción de competencias normativas, no se origine un vacio parcial del ordenamiento, permitiendo y prescribiendo, con este propósito, la aplicación supletoria, potencialmente indefinida, del ordenamiento estatal», lo que lleva al TC a «declarar nula y sin efecto la simultánea derogación expresa de la legislación urbanistica previa a la constitución de los órganos de poder de todas las Comunidades Autónomas llevada a cabo por el legislador estatal».

A pesar de la claridad de esta doctrina constitucional, y de que, en aplicación de la misma, recuperó vigencia el Texto Refundido de la Ley del Suelo de 1976, el TS declara derogado su artículo 122.1.a), lo que sólo puede sostenerse si se entiende que lo que él regula forma parte no de la materia «urbanismo» sino de la de competencia estatal con sede en el art. 149.1.1 ${ }^{\mathrm{a}}$ o $149.1 .13^{\mathrm{a}} \mathrm{CE}$, tesis que no se compadece ni con los antecedentes legislativos, ni con la regulación que -incluso con similares palabras a las del citado artículo del TRLS 76 que se declara derogado- del derecho de reintegro han hecho las Comunidades Autónomas, lógicamente en ejercicio de sus competencias en materia de «urbanismo», con la quietud del Estado que no ha planteado por ello conflicto alguno ante el Tribunal Constitucional. Con las dos sentencias que aquí se comentan el poder judicial devuelve al Estado la regulación de un ámbito material que los poderes legislativo y ejecutivo de aquél han consentido como propio de las Comunidades Autónomas.

\subsection{Sobre la pretendida distinción entre los deberes de los propietarios en la LRSV y el TRLS 76}

Dicho esto y volviendo al hilo argumental que se ha dejado pendiente, procede situar la cuestión en el art. 149.1.1 ${ }^{\text {a }} \mathrm{CE}$ y analizar si efectiva- 
mente la LRSV «se pronuncia sobre los deberes de los propietarios en forma diferente, en lo que ahora nos importa, a cómo lo hacía la legislación anterior», teniendo en cuenta que no es necesario comparar cómo se regulan todos los deberes porque el Tribunal Supremo ha extraído las diferencias sólo de los arts. 14.2.e) y 18.3 de la LRSV ( la «...cobertura legislativa la ofrecen los artículos...14.2.e) y 18.3 de la Ley 6/1998», fundamento jurídico séptimo.2 de la sentencia dictada en el recurso 154/2001). Así:

\begin{tabular}{|c|c|}
\hline LRS V & TRLS 76 \\
\hline $\begin{array}{l}\text { art. } 14.2 \text { («Deberes de los propietarios de suelo urbano») } \\
\text { «Ls propietarios de terrenos de suelo urbano que } \\
\text { carezcan de urbanización consolidada deberán } \\
\text { asumir los siguientes deberes: } \\
\ldots / \ldots \\
\text { e) Costear y, en su caso, ejecutar la urbanización» }\end{array}$ & $\begin{array}{l}\text { art. } 83.3 \\
\text { «os propietarios del suelo urbano deberán: } \\
\ldots / \ldots \\
2^{\circ} \text {.- Costear la urbanización» }\end{array}$ \\
\hline $\begin{array}{l}\text { art. } 18 \text { («Deberes de los propietarios de suelo urbanizable») } \\
\text { La trans formación del suelo clasifica do como urbani- } \\
\text { zable comportará para los propietarios del mis mo } \\
\text { los siguientes deberes: } \\
\ldots / \ldots\end{array}$ & $\begin{array}{l}\text { art. } 84 \\
\text { ¿os propietarios de suelo urbanizable programado de- } \\
\text { berán: } \\
\text {...... } \\
\text { c) Costear la urbanización» }\end{array}$ \\
\hline $\begin{array}{l}\text { 3.- Costeary, en su caso, ejecutar las infraestructuras } \\
\text { de conexión con los sistemas generales exteriores a la } \\
\text { actuación y, en su caso, las obras necesarias para } \\
\text { la ampliación o refuerzo de dichos sistemas requeri- } \\
\text { dos por la dimensión y densidad de la misma y las } \\
\text { intensidades de uso que ésta genere, de conformidad } \\
\text { con los requisitos y condiciones que establezca el } \\
\text { planeamiento general.» }\end{array}$ & $\begin{array}{l}\text { art. } 146 \text { (obligaciones mínimas de los propietarios de } \\
\text { sue lo urbanizable no programado, que podían ampliarse) } \\
\ldots / \ldots \\
\text { «b) Cons trucción de la red viaria completa de la zona de } \\
\text { actuación y de las redes de abastecimiento de agua } \\
\text { y energía eléctrica... } \\
\text { c) Construcción de las necesarias conexiones en el } \\
\text { exterior del a zona de actuación, con las redes } \\
\text { señaladas en el apartado anterior». }\end{array}$ \\
\hline
\end{tabular}

Al margen de las obviedades propias de la adaptación a un nuevo sistema propiciado por la LRSV (promoción pública o privada no reservada a los propietarios, que explica el recurso a la expresión «en su caso» del art. 14.2.E de la LRSV, y desaparición de la programación del suelo urbanizable, que funda la no separación entre el régimen de obligaciones del propietario según el suelo esté programado o no) los deberes relativos a la asunción por el propietario del coste de las obras de urbanización es el mismo en 1976 que en 1998. Por tanto, no se alcanza a adivinar qué hace afirmar al Tribunal Supremo que "frente a lo establecido en el Texto Unificado de 1976, (se) imponen al propietario de suelo urbano el deber de "costear y, en su caso, ejecutar la urbanización (art. 14.2.e) y al de suelo urbanizable el de costear y, en su caso, ejecutar las infraestructuras de conexión con los sistemas generales exteriores a la actuación y, en su caso, las obras necesarias para la ampliación o refuerzo de dichos sistemas requeridos por la dimensión y densidad de la misma y las intensidades de uso que ésta genere, de conformidad con los requisitos y condiciones que establezca el planeamiento general (art. 18.3)» (fundamento jurídico sexto de la sentencia dictada en recurso 154/2001) y que «...la Ley 
6/1998 modifica el tratamiento que, con anterioridad ella estaba vigente. Así resulta de su exposición de motivos y de los artículos 14.2.e) y 18.3 antes citados» (fundamento jurídico séptimo.1 de la misma sentencia) y menos, por tanto, se entiende que, a partir de estas afirmaciones y justamente con fundamento en ellas, se concluya que el derecho de reintegro ha quedado reducido a los límites en que lo fijan las sentencias comentadas.

Y otro dato a tener en cuenta para apreciar que los cambios que ha producido la LRSV permiten sostener que no han sido los que entiende el Tribunal Supremo: La regulación del derecho de reintegro nunca se ha contenido, sistemáticamente, junto con los deberes de los propietarios -que es lo que regula la LRSV-, como lo demuestra el hecho de que, en el derecho urbanístico estatal, el art. 122.1.a) del TRLS de 1976 esté encuadrado en el Título III, llamado «ejecución de los Planes de Ordenación», capítulo II, «de los sistemas de actuación»; y en el TRLS de 1992, el art. 155.1.a) titulado «gastos de urbanización», esté dentro del Título IV, «ejecución del planeamiento», capítulo II, «actuación mediante unidades de ejecución», es decir, en sede propia de la ejecución de la ordenación urbanística o de la transformación del suelo que concierne, sin duda, a la materia de competencia autonómica «urbanismo», como prueba el hecho de que la legislación autonómica sobre esta materia encuadre, recientemente de forma unánime, el derecho de reintegro en la misma sede de ejecución del planeamiento?.

Así pues, la única conclusión que cabe extraer es que, en relación con los deberes de los propietarios, no hay ningún cambio entre el TRLS 76 y la LRSV. El único cambio que el TS puede extraer es el de que como la

\footnotetext{
${ }^{9}$ De la legislación urbanística más reciente son de citar las siguientes normas con expresión de la ubicación sistemática de la regulación del derecho de reintegro: Extremadura: Ley 15/2001, de 14 de diciembre, del suelo y ordenación territorial de Extremadura, art. 127, «gastos de urbanización», integrado en el título IV, la ejecución del planeamiento de ordenación urbanística, capítulo II, la ejecución en unidades de actuación, sección $1^{a}$, disposiciones generales. Asturias: Ley 3/2002, de 19 de abril, de régimen del suelo y ordenación urbanística, art. 105, titulado «gastos de urbanización, integrado en el título $\mathrm{V}$, gestión urbanística, capítulo segundo, actuación mediante polígonos o unidades de actuación, sección $1^{a}$, disposiciones generales. Andalucía: Ley 7/2002, de 17 de diciembre, de ordenación urbanística de Andalucía, art. 113, titulado «gastos de urbanización», encuadrado en el título IV, sobre la ejecución de los instrumentos de planeamiento, capítulo II, la actuación por unidades de ejecución, sección 1 $1^{a}$, disposiciones generales. Navarra: Ley Foral 35/2002, de 20 de diciembre, de Ordenación del Territorio y Urbanismo, art. 139.1.a), titulado «gastos de urbanización», encuadrado en el título IV de la Ley, sobre ejecución de planeamiento, capítulo I, disposiciones generales, sección $1^{a}$, presupuestos y formas de ejecución. Galicia: Ley 9/2002, de 30 de diciembre, de ordenación urbanística y protección del medio rural de Galicia, art. 132 «gastos de urbanización», que forma parte del título IV, ejecución de los planes de ordenación, capítulo VI, sistemas de actuación, sección $1^{\mathrm{a}}$, disposiciones generales.
} 
LRSV no hace referencia alguna al derecho de reintegro que sí se mencionaba en el art. 122.1.a) del TRLS 76, éste ha desaparecido, lo que equivale a decir que su régimen de obligaciones se ha alterado por desaparición de un derecho de contenido económico, compensador de los deberes de urbanización, que ya no se recoge en la legislación estatal sino en la autonómica. De nuevo, la cuestión que ello suscita es si el derecho de reintegro es materia «urbanismo» y, por tanto, autonómica, o estatal con sede en el art. 149.1.1 CE.

\subsection{Sobre si el derecho de reintegro es materia «urbanismo»}

Para tratar de resolver tal cuestión, con un análisis de los antecedentes legislativos históricos (art. 3.1 Código Civil), es de ver, en primer lugar y como ya se ha dicho, que el derecho de reintegro en el Texto Refundido de 1976 el art. 122.1.a) está sistemáticamente ubicado dentro del título III de aquél, sobre la ejecución de los planes de ordenación, capítulo II referido a los sistemas de actuación. En el Texto Refundido de 1992, el Estado residenció el derecho de reintegro en el art. 155.1.a), incluido en el título IV, también sobre ejecución de planeamiento, capítulo II, dedicado específicamente a la actuación mediante unidades de ejecución.

A propósito de la materia «urbanismo», el Tribunal Constitucional (FJ 6 de la STC 61/1997), ha dicho que su contenido «se traduce en concretas potestades ...tales como las referidas al planeamiento, la gestión o ejecución de instrumentos planificadores ...» añadiendo que "el contenido que acaba de enunciarse se traduce en la fijación de lo que pudiéramos llamar políticas de ordenación de la ciudad...» y concluyendo que «...no debe perderse de vista que en el reparto competencial efectuado por la C.E. es a las Comunidades Autónomas a las que se ha atribuido la competencia exclusiva sobre el urbanismo, y por ende es a tales Entes públicos a los que compete emanar normas que afecten a la ordenación urbanística, en el sentido más arriba expuesto». A partir de esta declaración genérica, cuando el TC se enfrenta, en la citada Sentencia, con el enjuiciamiento de los preceptos del TRLS 92 referidos a la ejecución del planeamiento (que son los del título IV en el que está el art. 155 citado), dice (FJ 27.a) que «en rigor, estamos ante la ejecución urbanística del planeamiento que se inserta sin dificultad en el ámbito material del urbanismo». Cabe concluir, por tanto, que históricamente la regulación legal y sistemática del derecho de reintegro se ha insertado en la materia «urbanismo», ahora de competencia autonómica. 
Hasta tal punto ello es así que el propio legislador estatal lo entendió de ese modo cuando asignó carácter supletorio al art. 155.1.a) citado (Disposición final única del TRLS 92), aplicable, por tanto, «en defecto de regulación específica por las Comunidades Autónomas en ejercicio de sus competencias», razón por la cual, con base en los razonamientos ya citados, el TC declaró inconstitucional tal precepto (apartado $2^{\circ}$ del fallo).

En consecuencia, el Tribunal Supremo, por su cuenta, al extraer el derecho de reintegro del ámbito material del «urbanismo» ha ido más allá que el propio legislador estatal, como se viene sosteniendo, y ha traído al ámbito competencial propio de aquél un asunto que tanto el poder ejecutivo como el legislativo estatales habían dado por propio de las Comunidades Autónomas, como prueban dos datos: Primero, el hecho de que el Estado no haya cuestionado ante el Tribunal Constitucional la legislación autonómica urbanística reguladora del derecho de reintegro, ni siquiera la producida después del RD 1955/2000 (ver nota 9). Y segundo, el Estado no ha regulado positivamente tal derecho, lo que, conforme a los antecedentes legislativos históricos, parece razonable pensar que ha sucedido no con el propósito de eliminar tal derecho sino por entender que regularlo no forma parte de su esfera competencial.

Además, el que la regulación del derecho de reintegro sea materia de «urbanismo» fue admitido por el propio Tribunal Supremo cuando enjuicio la Orden de la Conselleria de Industria, Comercio y Turismo de la Generalitat Valenciana, de 17 de marzo de 1991, sobre extensión de redes eléctricas (Diario Oficial de la Generalitat Valenciana n. ${ }^{\circ} 1534$, de 3 de mayo de 1991) en la que se regulan las obligaciones de extensión de las redes eléctricas a cargo, según los casos, de las empresas suministradoras y de los propietarios, y se disciplina el contenido del derecho de éstos a su reintegro a cargo de las primeras (art. 6.4). En la Sentencia, de 27 de noviembre de 1995, RA 8870, (y después la de 24 de octubre de 2000, RA 8176) que resolvió el recurso interpuesto por las compañías eléctricas contra tal Orden, el Tribunal Supremo señala que la Administración autonómica tiene competencia para regular tal materia en virtud de lo que dispone el art. 31.9 del Estatuto de Autonomía de la Comunidad Valenciana, en lo referente a la ordenación del urbanismo, y en el art. 31.2.5 del mismo, en lo referente al desarrollo legislativo y ejecución del régimen energético en el marco de la legislación básica del Estado. Y no se puede decir que ésta sea una «jurisprudencia superada» (fundamento jurídico cuarto de la sentencia dictada en el recurso 157/2001, por ejemplo), toda vez que se refiere a títulos competenciales de procedencia constitucional que no han sufrido alteración alguna. 
En consecuencia, ni de los precedentes jurisprudenciales se deduce que le corresponda, ni el propio Estado (legislador o ejecutivo) ha reclamado ni activa ni pasivamente (el Estado no ha regulado el derecho de reintegro ni ha recurrido contra las leyes autonómicas que lo han hecho) un ámbito material que sólo vuelve a la esfera de competencia estatal como consecuencia de las Sentencias que aquí se comentan.

\subsection{El título competencial invocado por el TS para la eliminación del derecho de reintegro}

Y si el derecho de reintegro no puede, según se desprende de las sentencias comentadas, ser regulado por el Estado en ejercicio de sus inexistentes competencias en materia de urbanismo, estando regulado en el derecho estatal preconstitucional de este ámbito material, ¿al amparo de qué titulo competencial del Estado puede haber sido propiciada su eliminación?. La tesis del Tribunal Supremo se centra -dejando al margen el título competencial que proporcional el art. 149.1.25 ${ }^{\mathrm{a}}$ - en que «...el desarrollo reglamentario (el RD 1955/2000) se ha hecho en consonancia con la Ley 6/1998 que...impone a los propietarios del suelo la obligación de costear la urbanización, sin ningún tipo de repercusión sobre la empresa distribuidora, de tal forma que, aún para el hipotético caso de que se entendiera que ha habido una extralimitación respecto de la Ley 54/1997, la Ley posterior concede respaldo suficiente para la regulación que sobre las acometidas ha hecho el Reglamento» (fundamento jurídico quinto.II de la Sentencia dictada en el recurso 157/2001) o dicho de otro modo la «...cobertura legislativa la ofrecen los artículos...14.2.e) y 18.3 de la Ley 6/1998» (fundamento jurídico séptimo. 2 de la sentencia dictada en el recurso 154/2001). También es de tener presente el siguiente párrafo de la última sentencia citada: «...El Estado....puede dictar regulaciones como la que aqui examinamos. Regulaciones que, por otra parte, enlazan con las previsiones de la Ley 6/1998, aplicables en toda España y establecidas en virtud de la competencia estatal que reconoce la cláusula $13^{a}$ del artículo 149.1 de la Consitución...» (fundamento jurídico séptimo.2). Es decir, los títulos que parece entenderse proporcionan cobertura al Estado para haber querido, deliberadamente, suprimir el derecho de reintegro en la LRSV serían los del art.149.1.1 ${ }^{\mathrm{a}}$ y $149.1 .13^{\mathrm{a}} \mathrm{CE}$ que, ciertamente, han sido expresamente invocados en fundamento competencial del dictado de esta norma (Disposición Final Unica). 


\section{4.a. El título del art. 149.1.1 ${ }^{a} \mathrm{CE}$ :}

El título del art. $149 \cdot 1.1^{\mathrm{a}} \mathrm{CE}$ es el que proporciona base competencial a la regulación estatal de los derechos y obligaciones urbanísticas de los propietarios de suelo (Disposición Final Unica de la LRSV), cuyo supuesto nuevo régimen en la LRSV «se pronuncia sobre los deberes de los propietarios en forma diferente» (fundamento jurídico sexto de la sentencia dictada en el recurso 154/2001) a cómo lo hicieron las precedentes normas estatales y que lleva a concluir la actual inexistencia del derecho de reintegro. No obstante, conforme a la doctrina del Tribunal Constitucional, la regulación estatal de los derechos y deberes urbanísticos de los propietarios del suelo no puede conducir a la uniformidad que parece pretenderse para el derecho de reintegro de aquéllos frente a las compañías eléctricas, ni tampoco tal precepto constitucional priva a las Comunidades Autónomas de regular aquél. Así, la STC 61/1997, entre lo más significativo a este propósito, dice:

- «Este título estatal no representa, pues, una suerte de prohibición para el legislador autonómico de un trato divergente y desproporcionado respecto de la legislación estatal» (FJ 7.a).

- «...título competencial autónomo, positivo o habilitante, constreñido al ámbito normativo, lo que permite al Estado una «regulación», aunque limitada a las condiciones básicas que garanticen la igualdad, que no al diseño completo y acabado de su régimen jurídico» (FJ 7.b).

— «En definitiva ...el art. 149.1.1 ${ }^{a}$ C.E no debe ser entendido como una prohibición de divergencia autonómica...porque las condiciones básicas que garanticen la igualdad, por definición, no pueden consistir en un régimen acabado y completo de los derechos y deberes constitucionales afectados» (FJ 7.b).

- «...las condiciones básicas han de ser las imprescindibles o necesarias para garantizar esa igualdad, que no puede consistir en una igualdad forma absoluta» (FJ 8).

— «...el título del art. 149.1.1 ${ }^{\circ}$ C.E. no habilita para establecer una regulación uniforme de la propiedad privada y su función social, no esa pretendida uniformidad puede servir de pretexto para anular las competencias legislativas que las Comunidades Autónomas tienen sobre todas aquellas materias en las que entre en juego la propiedad» (FJ 9). 
DE NUEVO SOBRE EL DERECHO DE REINTEGRO DE LOS GASTOS DE ELECTRIFICACIÓN EN LOS PROCESOS...

- «A resultas de esas condiciones básicas, por tanto, el Estado puede plasmar una determina concepción del derecho de propiedad urbana, en sus líneas más fundamentales...Las Comunidades Autónomas, desde la competencia urbanística que les reconocen la Constitución y los Estatutos de Autonomía, podrán dictar normas atinentes al derecho de propiedad urbana, con respeto, claro está de esas condiciones básicas y de las demás competencias estatales» (FJ 10).

- Finalmente, la falta de uniformidad que pudiera surgir de la diversa regulación autonómica del derecho de reintegro tampoco es contraria a la Constitución: «Ha de admitirse, pues, la posibilidad de que las normas dictadas por el legislador estatal ex art. 149.1.1 ${ }^{a}$ $C E$, lejos de un riguroso uniformismo, puedan razonablemente introducir regulaciones o tratamientos diferenciados en presencia de elementos o factores objetivos, como pudiera ser en el caso, el poblacional, siempre, claro está, dentro del ámbito de sus competencias. No podría, por ello, tacharse de inconstitucionalidad un modo de regulación así configurado» (FJ 41.a).

Y de la STC 164/2001, que se pronuncia sobre la constitucionalidad de la LRSV, se debe destacar lo siguiente «...debemos recordar que las Comunidades Autónomas son titulares, en exclusiva, de las competencias sobre urbanismo. La competencia legislativa sobre urbanismo permite a las Comunidades Autónomas fijar sus propias politicas de ordenación de la ciudad y servirse para ello de las técnicas jurídicas que considere más adecuadas. Una de esas técnicas jurídicas puede ser, entre otras, la definición o conformación de las facultades urbanísticas de la propiedad urbana» (FJ 4).

El que, a la vista de tales pronunciamientos del TC, el legislador del Estado no ha querido esa uniformidad en los derechos y deberes de los propietarios de todo el territorio nacional se prueba con la simple invocación de los arts. 14.2.c) y 18.4 de la LRSV en los que, al disponer la obligación de los propietarios de ceder a la Administración una parte de los aprovechamientos urbanísticos del correspondiente ámbito, deja en manos de las Comunidades Autónomas la concreción de esa porción ceder, sin rebasar el máximo el 10 por 100, así como la de «reducir la participación de la Administración actuante en las cargas de urbanización que correspondan a dicho suelo».

En consecuencia, si el Estado no ha podido derogar expresamente su propio derecho preconstitucional en materia de urbanismo en el particular 
que se refiere al derecho de reintegro, tal como resulta de la doctrina del TC en sentencia 61/1997, tampoco el art. 149.1.1 ${ }^{\text {a }} \mathrm{CE}$ parece proporcionarle cobertura para la eliminación de tal derecho por la vía indirecta propuesta por el Tribunal Supremo de haber producido, mediante la LRSV, un nuevo régimen de derechos y obligaciones de los propietarios en el que no figura el reintegro de los costes de electrificación que soporten con ocasión de la transformación del suelo, pues tal régimen, en los términos que se acaban de ver, no es completo y acabado, permite una legislación autonómica divergente que mantenga la plena existencia del derecho, lo que confronta con el criterio del Tribunal Supremo que lo confina al siguiente reducto: «no hay infracción de la distribución de competencias entre el Estado y las Comunidades Autónomas. Por lo demás, cuanto se ha dicho no quiere decir que queden sin contenido las normas autonómicas que afirman la existencia de un derecho de los propietarios a reintegrarse de estos gastos. En efecto, sucede que, por debajo de los umbrales de potencia a los que se refiere el artículo 45.1 (del RD), son directamente las distribuidoras las que deben asumirlos. Además, las reglas autonómicas invocadas por la actora no solo se refieren a las instalaciones para el suministro de energía. De ahí que, tratándose de otros suministros, pueda caber una solución diferente...» (fundamento jurídico séptimo.2 de la sentencia dictada en el recurso 154/2001 y, en el mismo sentido, fundamento jurídico quinto.II de la dictada en el recurso 157/2001).

\section{4.b. El título del art. 149.1.13a:}

Si el art. 149.1.1 ${ }^{\mathrm{a}} \mathrm{CE}$ no puede prestar cobertura a la regulación estatal de un pleno derecho de reintegro, ¿la ofrece el art. 149.1.13 ${ }^{\text {a }}$ CE?. Este precepto dispone que el Estado tiene competencia exclusiva sobre las «bases y coordinación de la planificación general de la actividad económica», y los límites genéricos en que tal competencia se ha establecido por la doctrina del Tribunal Constitucional son los siguientes:

1. En el ejercicio de esa competencia no pueden resultar vaciadas de contenido, o limitadas irrazonablemente, las correspondientes competencias autonómicas (STC 103/1989, de 8 de junio; STC 45/1991, de 28 de febrero), en particular, la coordinación no puede entrañar apoderamiento alguno a favor del Estado para normar directamente el ámbito material sobre el que la coordinación se establece (STC 106/1987, citada en la primera de las dos antes mencionadas).

2. La competencia puede prestar cobijo a normas que fijen líneas directrices y criterios globales de ordenación de sectores económicos, así 
como las previsiones de acciones o medidas singulares que sean necesarias para alcanzar los fines propuestos dentro de la ordenación de cada sector (STC 145/1989, de 21 de septiembre, que cita la $152 / 1988)$.

Por su parte, la específica relación del título del art. 149.1.13 con el urbanismo ha sido también analizada por el Tribunal Constitucional y resumida en sus sentencias 61/1997 (FJ 24.d y 36) y 164/2001 (FJ 9). Tomamos de la primera (FJ 36) los siguientes párrafos: «El problema radica, sin embargo, en determinar el alcance de esa competencia cuando, como es el caso, incide sobre una competencia autonómica sectorial...» de lo que el TC concluye, sobre la base de la precedente STC 213/1994, una «...inteligencia restrictiva del art,. 149.1.13 ${ }^{a}$ CE cuando afecta a la competencia urbanística de las Comunidades Autónomas ...de modo que tan sólo aquellas normas básicas que respondan efectiva y estrictamente a la planificación general de la actividad económica podrían encontrar cobijo en el referido título, que impide la producción de normas que, aunque relacionadas con esa planificación general, no guarden esa inmediata relación con la dirección de la economía». De la segunda interesa destacar, además de su remisión al anterior criterio restrictivo, lo siguiente «No cuestionamos que la transformación urbanística del suelo sea una actividad económicamente relevante pero sí que la simple previsión de dirección pública en el proceso urbanizador tenga consecuencias económicas directas. Además, la transformación urbanística del suelo es sin discusión uno de los núcleos centrales que integran la materia «urbanismo». Y también conviene poner de manifiesto que el único precepto de los de la LRSV cuestionados respecto del cual se examina su relación con el 149.1.13 ${ }^{\mathrm{a}} \mathrm{CE}$ es el art. 4 (acción urbanística e iniciativa privada). Los arts. 14.2.e) y 18.3 de la LRSV, en los que el Tribunal Supremo ve un nuevo régimen de propiedad que excluye el derecho de reintegro, o no fueron impugnados ante el Tribunal Constitucional (caso del art. 14.2.e, FJ 21 de la STC 164/2000) o lo fueron por razones formales derivadas del empleo de las expresiones «sistemas generales» y «planeamiento general», que no vienen al caso.

Así las cosas, al amparo de este título (art. 149.1.13a CE) el Estado no parece que pueda haber eliminado la regulación autonómica del derecho de reintegro porque estando insertado éste en la regulación de los procesos de transformación urbanística, y referido expresamente a éstos -como además lo está en la legislación estatal-, forma parte del urbanismo, materia de competencia autonómica, en la que el legítimo ejercicio del citado título competencial por parte del Estado se debe limitar, con la perspectiva restrictiva que ha acunado el Tribunal Constitucional, a fijar líneas 
directrices y criterios globales que no puede entrañar apoderamiento alguno a favor del Estado para normar directamente el ámbito material sobre el que la coordinación se establece. Y sin que tampoco se pueda ver que la regulación del derecho (para ordenarlo positivamente, suprimir el preexistente o modularlo), por el muy restringido ámbito subjetivo de su aplicación y su relativa trascendencia económica en el complejo proceso de transformación del suelo, tenga relación efectiva y estricta con la planificación general de la actividad económica, en esa línea de principios (no agotadora) que es propia de las bases y de la coordinación a que se refiere este título.

\section{SOBRE LO QUE EL TRIBUNAL SUPREMO SILENCIA DEL RÉGIMEN CONTENIDO EN EL RD}

El recurso 157/2001 se dirige (antecedente de hecho segundo y fundamento jurídico primero de la sentencia que lo resuelve) contra todo el Real Decreto, con la pretensión principal de que se anule todo él; alternativa y subsidiariamente se dirige la impugnación contra el capítulo II, del Título III y alternativa y subsidiariamente, los artículos 44 y 45 de tal norma. Por su parte, el recurso 154/2001 se dirige (antecedente de hecho segundo) contra el art. 45, excepto el apartado 7, y el art. 47.5, con la pretensión de que se declaren nulos y dejen sin efecto.

Para centrar el análisis que aquí se acomete, conviene precisar que, por el contenido de este trabajo y de las pretensiones deducidas en ambos recursos, aquí sólo se hace referencia a los arts. 45, apartados 1,2 y 3 , y 47.5 , normas que, además, se copian en los fundamentos jurídicos tercero de la sentencia dictada en recurso $154 / 2001$ y primero de la sentencia dictada en recurso 157/2001.

El art. 45.1 dispone, en lo que interesa aquí, lo siguiente: «La empresa distribuidora que haya de atender un nuevo suministro o la ampliación de uno ya existente estará obligada a la realización de las infraestructuras eléctricas necesarias cuando dicho suministro se ubique en suelo urbano que tenga la condición de solar...

Cuando la instalación de extensión supere los límites de potencia anteriormente señalados, el solicitante realizará a su costa la instalación e extensión necesaria, de acuerdo con las condiciones técnicas y de seguridad reglamentarias, como con las establecidas por la empresa distribuidora y aprobadas por la Administración competente. En estos casos las instalaciones de extensión serán cedidas a una empresa distribuidora...» 
Interesa subrayar la contraposición que representa la expresión «La empresa distribuidora...estará obligada a la realización de las infraestructuras eléctricas necesarias cuando dicho suministro se ubique en suelo urbano que tenga la condición de solar...» de la que deriva la residencia subjetiva en las compañías eléctricas del deber de dotar de este servicio, respecto del régimen que resulta del art. 14.1 de la LRSV que atribuye a los propietarios del suelo urbano consolidado por la urbanización, concepto a estos efectos equivalente al de suelo urbano que tenga la condición de solar, el deber de completar a su costa la urbanización necesaria para que los terrenos alcancen la condición de solar; contraposición que alcanza virtualidad relevante en los casos de obsolescencia de la urbanización y necesidad de nueva provisión de la misma para atender nuevas demandas, que, si nos atenemos al artículo que se comenta, deja de estar en manos del propietario para pasar a la de las compañías eléctricas, alterando obviamente el régimen legal mediante norma con rango jerárquico insuficiente para ello.

El art. 45.2 del RD dispone: «Cuando el suministro se solicite en suelo urbano que no disponga de la condición de solar de acuerdo con lo dispuesto en la Ley 6/1998, de 13 de abril, sobre régimen del suelo y valoraciones, su propietario deberá completar a su costa, de acuerdo tanto con las condiciones técnicas y de seguridad reglamentarias, como con las establecidas por la empresa distribuidora y aprobadas por la Administración competente, la infraestructura eléctrica necesaria para que se adquiera tal condición, aplicándose, en su caso, lo previsto en el apartado anterior».

En relación con el dictado de este precepto, y más en concreto su referencia a un determinado supuesto de hecho («suelo urbano que no disponga de la condición de solar») con expresa remisión a «lo dispuesto en la Ley 6/1998, de 13 de abril, sobre régimen del suelo y valoraciones», lo deja vacío de contenido e inaplicable por imposibilidad de integrar tal supuesto en la norma de remisión que, en ningún momento, establece al concepto de solar, por ser éste encuadrable en la materia de competencia autonómica «urbanismo» ${ }^{10}$.

\footnotetext{
10 En este orden de cosas: Juan Cruz Alli Arangueren, «De la Sentencia el Tribunal Constitucional de 20 de marzo de 1977 a la Ley 6/1998, de 13 de abril, de Régimen del Suelo y Valoraciones», en Documentación Administrativa, n. ${ }^{\circ}$ 252-253, p. 441: «si, por el contrario, los contemplados (sic) como términos puramente instrumentales...no pueden llegar a fijar el régimen jurídico de las dotaciones públicas, de los solares o de las licencias de edificación, no se ven afectadas de inconstitucionalidad», añadiendo que «el término solares parece como denominación de los terrenos de suelo urbano con urbanización completa (art. 13), cuyas condiciones no se precisan, lo que queda para la legislación urbanística. Tal condición es la base del derecho a edificar (arts. 13,14.2.f y 18.7). Su
} 
Sin perjuicio de lo anterior y en relación con este asunto ya dijimos (trabajo citado en nota 1) que: «El texto reglamentario ha venido, por tanto, a configurar un concepto urbanístico (el de solar) al establecer que sólo cuando éste tenga completa una determinada infraestructura (la eléctrica) alcanzará aquella condición. Ni siquiera el Texto Refundido de la Ley del Suelo de 1976 se atrevió a tanto, pues en éste, al definir el concepto de solar (art. $82.1^{\circ}$ ) se remitió a las normas que, en su caso, estableciese el planeamiento correspondiente, igual como hizo el Texto Refundido de la Ley del Suelo de 1992 en su artículo 14 que resultó declarado inconstitucional por la Sentencia del TC 61/1997, de 20 de marzo, precisamente por el carácter supletorio de dicho precepto.» Sorprende ahora, por tanto, que la configuración del concepto de solar que se contiene en el art. 45.2 del RD al decir que los terrenos sólo alcanzarán tal condición cuando la dotación del servicio eléctrico se efectúe «de acuerdo tanto con las condiciones técnicas y de seguridad reglamentarias, como con las establecidas por la empresa distribuidora y aprobadas por la Administración competente», haya dejado de tener el carácter supletorio que tenía en la legislación estatal última citada y se eleve su rango al básico que deriva de la Disposición Final Primera.1 del propio RD, sin que ello haya merecido la atención del Tribunal Supremo en las sentencias aquí comentadas y que expresamente enjuician este precepto.

También hemos dicho (en el trabajo citado) al comentar este artículo 45.2 del RD que "Parece fuera de toda duda que el Gobierno ha adoptado una medida de carácter urbanístico (la configuración del concepto de solar) en una norma dictada al amparo de títulos competenciales que no habilitan para incidir en esa materia, ni siquiera indirectamente como ha hecho la LRSV, y con clara invasión de las competencias urbanisticas autonómicas y municipales que, indefectiblemente, han de entender restringida su capacidad para determinar bajo qué circunstancias de dotación de servicios unos terrenos determinados adquieren la condición de solar, no tanto porque el RD que se comenta exija que entre aquéllos esté el servicio eléctrico, sino porque el $R D$ exige que éste se provea de un modo concreto y determinado, esto es, de acuerdo tanto con las condiciones técnicas y de seguridad reglamentarias, como con las establecidas por la empresa distribuidora y aprobadas por la Administración competente». Este pormenorizado nivel de detalle en la regulación básica que

utilización por el legislador estatal es instrumental, mientras que su contenido material corresponde al autonómico.» Y José Ma BAÑo León, en «La nueva Ley del Suelo y la Sentencia del Tribunal Constitucional de 20-3-1997», en la misma revista y número, p. 161: «...la ley (la LRSV) no dice qué debe entenderse por suelo urbano consolidado ni qué alcance jurídico tiene la denominación de solar, de modo que tales definiciones competen a la legislación de las CC.AA.» 
acomete el Estado no se compadece con los límites de su competencia que «no puede llegar a fijar el régimen jurídico de las dotaciones públicas, de los solares o de las licencias de edificación» (FJ 17.b in fine, de la STC 61/1997), en relación con lo cual también hemos invocado la doctrina pertinente, siendo de añadir que, con la configuración del concepto de solar que se hace en el RD, se está regulando también el momento de la edificación asunto para el que el Estado tampoco tiene competencia a la luz de la STC citada, según la cual:

a) «el urbanismo...alude a la disciplina jurídica del hecho social o colectivo de los asentamientos de población en el espacio físico, lo que en el plano jurídico, se traduce en la «ordenación urbanistica»...el contenido el urbanismo se traduce en concretas potestades (en cuanto atribuidas a o controlados por Entes públicos), tales como las referidas al planeamiento, la gestión o ejecución de los instrumentos planificadores y la intervención administrativa en las facultades dominicales sobre el uso del suelo y edificación, a cuyo servicio se arbitran técnicas jurídicas concretas; a lo que ha de añadirse la determinación, en lo pertinente, del régimen jurídico del suelo en tanto que soporte de la actividad transformadora que implica la urbanización y edificación.

El contenido que acaba de enunciarse se traduce en la fijación de lo que pudiéramos llamar políticas de ordenación de la ciudad, en tanto en cuanto mediante ellas se viene a determinar el cómo, cuándo y dónde deben surgir o desarrollarse los asentamientos humanos, y a cuyo servicio se disponen las técnicas e instrumentos urbanísticos precisos para lograr tal objetivo» (FJ 6.a).

b) «Este título competencial no permite, pues, la delimitación completa y acabada del aprovechamiento urbanistico (como de cualquier otra facultad dominical en el ámbito urbanistico), pues ello excedería por definición de lo que son condiciones básicas de ejercicio, único título que, desde la óptica del Derecho público, le permita al Estado intervenir en los términos ya conocidos sobre esta concreta forma de dominio, cual es la propiedad urbana» (FJ 17.c).

A propósito del art. 45.3, regulador de obligaciones del propietario del suelo urbanizable, se ha de reproducir lo dicho en relación con el apartado 2 del mismo artículo, siendo de destacar los efectos que el precepto produce en la reducción de las competencias de las Administraciones urbanísticas (señaladamente la local) para determinar las condiciones de desarrollo de tal clase de suelo de acuerdo con el planeamiento que des- 
arrolle el modelo de ocupación el territorio que legítimamente corresponde decidir a las autoridades de los Entes Locales en el marco de las competencias supramunicipales. No otra cosa se puede deducir de la llamada que el precepto que se comenta hace a «la empresa distribuidora» para establecer condiciones técnicas y de seguridad de la extensión de redes y la propia necesidad de las mismas.

El art. 47.5, finalmente, dispone, en su último párrafo, que «en los supuestos de actuaciones urbanísticas, el suelo necesario para subestaciones y el suelo o locales destinados a centros de transformación, no computando a efectos de volumetría, se definirán como servicios dotacionales, en su caso infraestructuras básicas de suministro, y serán costeados por el promotor o urbanizador», en relación con lo cual, además de lo ya dicho (en nuestro trabajo señalado en nota 11) -predeterminación de la calificación dotacional y sólo ella que se ha de dar a determinados terrenos e incidencia en técnicas e instrumentos urbanísticos, todo ello ajeno al contenido material competencia del Estado-, es necesario precisar que la expresión "serán costeados por el promotor o urbanizador», impone una obligación a sujetos ajenos a la propiedad del suelo (que es en quien la LRSV residencia los deberes) lo que, a su vez, predetermina el modelo de ejecución del planeamiento mediante un promotor o urbanizador o la obligada conversión en uno u otro por parte el propietario. Todo ello se compadece mal con la doctrina de la STC 61/1997, que señala:

a) «...la competencia del Estado para establecer unos deberes básicos no puede llegar a fijar el régimen jurídico de las dotaciones públicas, de los solares o de las licencias de edificación». (FJ 17.b).

b) "...excede de la competencia estatal...toda una serie de técnicas estrictemente urbanísticas sobre las que el Estado carece de competencia....(aprovechamiento tipo, áreas de reparto, la concreta configuración de la división del aprovechamiento lucrativo por su superficie total, etc) e imponiendo además de forma vinculante determinadas operaciones (inclusiones o exclusiones del dotacional; coeficientes de ponderación, etc).» (FJ 24.b).

c) «las Comunidades Autónomas pueden establecer su propio sistema de ejecución del planeamiento urbanístico». (FJ 27).

d) «los apartados...del artículo... establecen cuándo y cómo se producen las cesiones obligatorias y gratuitas, lo que pertenece a la competencia de las Comunidades Autónomas en materia de urbanismo...» (FJ 29.b). Y 
e) «El Estado carece de competencias para establecer cuál o cuáles son las vías necesarias e indisponibles para obtener terrenos dotacionales». (FJ 30).

Y tampoco se ajusta el art. 47.5 a lo dicho por el Tribunal Constitucional en Sentencia 164/2001. Así:

a) «...lo que cabalmente impone el art. $4.2 \mathrm{LRSV}$, un mandato de promoción de la participación privada alli donde la actuación urbanistica no sea particular, sino administrativa. En el precepto impugnado no se impone sistema alguno de ejecución, tampoco se predetermina quién, cómo o cuándo se puede o debe participar. Estas opciones normativas corresponden al legislador autonómico» (FJ 9).

b) «En consecuencia, será cada Comunidad Autónoma, al fijar los criterios de consolidación por urbanización, quien determine también qué suelo urbano soportar deberes de cesión y cuál no» (FJ 20).

Esta confrontación del RD con las leyes y con la doctrina del Tribunal Constitucional interpretativa del reparto de competencias que resulta del texto constitucional, permitiría ante los Jueces y Tribunales, conforme al art. 6 de la Ley Orgánica del Poder Judicial, fundar pretensiones de inaplicabilidad de estos particulares del RD.

¿Puede la Administración hacer lo mismo, es decir, inaplicar los particulares del $\mathrm{RD}$ que aquí se han confrontado con la doctrina del TC? ${ }^{11}$. Abonaría la tesis de la inaplicación (en el sentido no sólo de potestad administrativa sino de deber) por la propia autoridad de la Administración, las exigencias:

a) De sometimiento pleno y directo de las Administraciones pública, no sólo a la Ley, sino al derecho entero (art. 103.1 CE).

b) De responsabilidad que la Administración asume y que supone el ejercicio conforme a derecho de sus propias competencias que no puede descargar sobre otro sujeto planteando cuestiones de inconstitucionalidad o de ilegalidad.

c) De celeriad de la actividad administrativa.

d) De necesidad de evitar el riesgo de que normas de mayor valor y jerarquía que las inaplicadas queden provisionalmente privadas de efecto.

\footnotetext{
11 En este orden de cosas: «La inaplicación administrativa de Reglamentos ilegales y Leyes inconstitucionales», de G. DomÉnECH PASCUAL, en RAP, n. ${ }^{\circ}$ 155, mayo-agosto 2001, pp. 59 a 106.
} 
Si se entiende que el derecho de reintegro es materia autonómica «urbanismo», la Comunidad Autónoma debe inaplicar una norma reglamentaria que afecta a una competencia asignada y asumida constitucional y estatutariamente. Dicho de otro modo: La inaplicación supone el ejercicio normal y conforme a derecho de la propia competencia sobre «urbanismo». Es decir, para ejercer las competencias que el ordenamiento les ha otorgado y actuar sus propias disposiciones sobre el derecho de reintegro, contenidas en las normas urbanísticas autonómicas, se deben inaplicar otras normas de menor rango y dudosa conexión con la esfera de competencias reservadas por la Constitución a quien las ha dictado.

\section{SOBRE EL TRATAMIENTO QUE EL TRIBUNAL SUPREMO HACE DEL PRINCIPIO DE INTERDICCIÓN DEL ENRIQUECIMIENTO INJUSTO}

Con todo, destaca en la argumentación de las sentencias todo lo relativo al tratamiento del enriquecimiento injusto, por su falta de apoyo en disposiciones legales, por su inadecuación a la realidad y por lo controvertible de las afirmaciones que en tal argumentación se expresan.

Las partes recurrentes, en sus demandas, plantearon que si los propietarios del suelo ejecutaban a su costa la infraestructura eléctrica y la cedían a la correspondiente compañía distribuidora, con coste nulo para ésta, se produce un enriquecimiento injusto en el patrimonio de ésta (fundamento de derecho tercero.III de la sentencia dictada en el recurso $157 / 2001$ y quinto. 9 de la dictada en el recurso 154/2001).

No es extraña esa invocación de las actoras en los citados recursos por cuanto, doctrinal y jurisprudencialmente, la observancia del principio de interdicción del enriquecimiento injusto siempre había aparecido como argumento de cierre de las pretensiones de reintegro a cargo de las compañías eléctricas ${ }^{12}$.

\footnotetext{
12 La idea de interdicción del enriquecimiento injusto está presente en las declaraciones de los Tribunales. Así: «...preceptos que están poniendo de manifiesto que el mantenimiento de las líneas conductoras en condiciones idóneas para atender las demandas normales de suministro -o en su caso el refuerzo de las mismas con este fin- no puede repercutirse a los usuarios porque forma parte de las empresas y de las inversiones para atender las solicitudes de consumo de energía, que constituyen la base de su particular negocio, no siendo olvidable que las instalaciones de la red de distribución, son en todo caso, propiedad de la Compañía suministradora...comportando la obligación de mantener, extender y ampliar, al menos en suelo urbano...la red de distribución de energía eléctrica, no sólo la realización de la extensión y ampliación, sino que se efectúe con cargo a la empre-
} 
Las sentencias que se comentan abordan este asunto en diversos pasajes de sus fundamentos jurídicos, aunque donde de manera más completa se trata es en el fundamento de derecho quinto.III de la sentencia dictada en el recurso 157/2001 (en el fundamento de derecho séptimo.9 de la sentencia que resuelve el recurso 154/2001, se contienen sólo parte de los argumentos de aquélla), si bien el anticipo de la posición del Tribunal en relación con este asunto ya puede verse al principio de la argumentación cuando, en el fundamento jurídico cuarto de la sentencia del recurso 157/2001, se dice que el régimen jurídico del suministro de electricidad ha cambiado sustancialmente en la última década, de modo que «frente al anterior sistema de servicio público de titularidad estatal desarrollado por el Estado mediante una sociedad de mayoría pública, se tiende en la actual normativa ... a la liberalización y libre competencia del sector eléctrico», de lo que el Tribunal deduce que «ya se encuentran superados los criterios que regían en la época anterior...e igualmente debe considerarse superada la jurisprudencia recaída en aplicación de los mismos...», en lo que es de ver una determinada posición intelectual ya que, bajo el régimen de servicio público de titularidad estatal sí ha venido admitiéndose la repercusión final de los costes de electrificación en las compañías eléctricas y, sorprendentemente, bajo el régimen actual de libre competencia se organiza toda una estructura jurídica positiva y se añade a la misma una fundamentación adicional para que esa repercusión ya no sea posible.

Sin perjuicio de ello, como se ha dicho, el tratamiento de la hasta ahora exitosa invocación del principio de interdicción del enriquecimiento injusto se recoge en el fundamento de derecho quinto.III de la sentencia dictada en el recurso 157/2001, con las siguientes palabras:

«La configuración de la distribución eléctrica como un servicio universal obliga al distribuidor a llevar el suministro de energía a cualquier punto del territorio en que opere, sea o no rentable, e independientemente de que la urbanización a la que vaya a dar nuevo servicio fructifique o no en viviendas o industrias que supongan un consumo tarifable ${ }^{13}$. Este riesgo,

sa suministradora, de tal modo que el particular sólo precise construir la acometida individual» (STS de 27.11.95, RA 8870 y 24 de octubre de 2000, RA 8176).

${ }^{13}$ Contrastan con el panorama que dibuja la Sentencia los resultados económicos de las empresas eléctricas que las que se puede tener noticia por la prensa diaria. En concreto, la página web de IBERDROLA, que en el mercado liberalizado de energía eléctrica tiene el 38,3 por 100 de cuota de mercado (9,4 millones de clientes en España en la actividad de distribución), dice, el 10 de febrero de 2004, que su beneficio neto creció en 2003 un 10,1 por 100, alcanzado los 1.060 millones de euros; el beneficio operativo aumentó en el mismo año un 16,6 por 100. En la misma página dice que en distribución IBERDROLA ha gastado en España, en 2003, 519 millones de euros. Recientemente, no obstante, se solicita la revisión del sistema de retribución de las compañías eléctricas; en este sentido R. GÓMEZ-FERRER RINCÓN, en «El déficit de ingresos en el sector eléctrico», en RAP n. ${ }^{\circ} 162$, septiembre-diciembre de 2003, pp. 307 y ss. 
que debe soportar por ministerio de la Ley, conforme ha quedado dicho, compensa en cierta medida la adquisición de la titularidad de las nuevas lineas $y$, aunque por esta vía se enriquezca su patrimonio, no es injustamente, si se tiene en cuenta que pesan sobre él los gastos derivados del mantenimiento de las instalaciones en forma que garanticen la calidad y continuidad del suministro, gasto del que se ve liberado el promotor y propietario si hubiera de conservar la propiedad de las infraestructuras eléctricas.

Por otro lado, es indudable que el dueño que cede las instalaciones obtiene como consecuencia del suministro de electricidad que éstas hacen posible y, en general, del derecho a edificar en el marco del planeamiento urbanistico, una plusvalia que le compensa.»

Toda esta argumentación, en la que no luce ni una sola cita legal o reglamentaria que la apoye, es altamente criticable, comenzando por la diferente óptica con la que se consideran los beneficios de las empresas eléctricas y las de los propietarios del suelo.

En efecto, el Tribunal entiende que las primeras asumen un «riesgo», por ministerio de la ley, cuando proceden a la extensión de las redes a cualquier parte del territorio y que no se sabe cierto si se verá compensado con facturaciones por consumo. En cambio, respecto del propietario del suelo costeador de las infraestructuras eléctricas, no hace hipótesis sobre el beneficio que da por supuesto se produce («es indudable», dice, que obtiene una plusvalía).

Con este modo de razonar, en principio, se pasa por alto que, en el actual sistema libre de mercado de energía eléctrica con unas reglas que lo disciplinan marcadas transparentemente por la legislación sectorial, el riesgo empresarial asumido por quien pretende dedicarse a la distribución eléctrica, con esas cargas a que se refiere la sentencia, es libre y conscientemente asumido y, para las compañías que ya lo estuviesen haciendo conforme al régimen anterior (en el que se solía concentrar en una misma empresa, personificada jurídicamente en una sola compañía mercantil, la producción y distribución), se prevén importantes compensaciones económicas como coste de transición a la competencia (Disposición Adicional Sexta de la LSE, modificada por la Ley 9/2001, de 4 de junio) ${ }^{14}$ al margen de subvenciones con fondos públicos destina-

\footnotetext{
${ }^{14}$ La Ley 9/2001, de 4 de junio, de modificación, entre otros preceptos, de la Disposición Adicional Sexta de la LSE, señala en su exposición de motivos que «en el caso concreto del sector eléctrico, hay que señalar que en estos tres últimos años se ha ido produciendo una aceleración en la liberalización del suministro, estando previsto, de acuerdo con el Real Decreto-ley 6/2000, de 23 de junio, de medidas urgentes de intensificación de la competencia en mercados de bienes y servicios, la total liberalización del suministro el 1 de enero de 2003.
} 


\title{
das a atender precisamente la extensión de redes en el medio rural donde la facturación por consumo puede no llegar a equilibrar el coste de la
}

\begin{abstract}
A su vez, este ambicioso plan de liberalización ha ocasionado que empresas, que hasta la fecha no habían considerado su implantación en España, están interesadas en participar en la apertura del mercado del suministro de electricidad.

Para ello, el Gobierno considera imprescindible aclarar el marco aplicable a los costes de transición al régimen de mercado competitivo para los titulares de instalaciones de producción de energía-

impuesto por la disposición transitoria sexta de la Ley 54/1997, de 27 de noviembre, del Sector Eléctrico, y sus sucesivas modificaciones...».

El segundo párrafo de los transcritos, que está nada menos que en una Ley, hace pensar que los inversores extranjeros, a pesar del pesimismo del Tribunal Supremo que se trasluce en sus manifestaciones («la distribución eléctrica como un servicio universal obliga al distribuidor a llevar el suministro de energía a cualquier punto del territorio en que opere, sea o no rentable, e independientemente de que la urbanización a la que vaya a dar nuevo servicio fructifique o no en viviendas o industrias que supongan un consumo tarifable») han visto, razonablemente, «negocio» en el sector eléctrico español.
\end{abstract}

A partir de esas consideraciones, el nuevo texto de la citada Disposición Transitoria dice, entre lo más significativo, lo siguiente:

1.- Se reconoce la existencia de unos costes de transición al régimen de mercado competitivo, previsto en la presente Ley, de las sociedades titulares de instalaciones de producción de energía eléctrica que a 31 de diciembre de 1997 estuvieran incluidas en el ámbito de aplicación el Real Decreto 1538/1987, de 11 de diciembre, sobre determinación de la tarifa de las empresas gestoras del servicio. En consecuencia, se reconoce a dichas sociedades el derecho a percibir una compensación por tales costes.

El importe base global de dichos costes, en valor a 31 de diciembre de 1997, nunca podrá ser superior a 1.736 .778 millones de pesetas,

4.- Los costes que se deriven e esta retribución serán repercutidos a todos los consumidores de energía eléctrica como costes permanentes del sistema...».

En el orden de las subvenciones, por ejemplo, en la Comunidad Valenciana hay un Plan específico (el Plan Valenciano de Electrificación Rural) que tiene por objeto atender las necesidades de suministro energético de los núcleos de población aislados y las explotaciones que aún quedan por electrificar, conectándolas a las redes de suministro existentes y destinando para ello una parte significativa de los recursos disponibles a las instalaciones que suministren energía eléctrica a los habitantes del medio rural. La concreta ayuda financiera a este tipo de actuaciones se articula a través de la convocatoria anual de ayudas para la electrificación rural. Para 2004, tales ayudas han sido convocadas por Orden de 15 de diciembre de 2003, de la Conselleria de Infraestructuras y Transporte (DOGV n. ${ }^{\circ} 4659$, de 29.12.03), en cuyo preámbulo se lee: «El aislamiento de algunas comarcas y zonas del interior de la Comunidad Valenciana, al que han contribuido decisivamente determinados déficits de infraestructuras, entre ellas las energéticas, incide en el nivel y calidad de vida de sus habitantes y genera situaciones de desventaja económica comparativa para las actividades productivas de esas comarcas, frenando tanto su capacidad de desarrollo endógeno como la localización de industrias y empresas en dichas comarcas. Ello hace aconsejable la intervención pública en forma de ayudas de la administración autonómica destinadas a la mejora de las infraestructuras energéticas. Estas ayudas se dirigirán a la cofinanciación de proyectos de electrificación rural que contribuyan a la mejora de la calidad de vida de los habitantes del medio rural y al desarrollo de actividades productivas, tanto del sector primario y agroalimentario, como de la industria, turismo, artesanía y servicios» y conforme con ello, en el texto articulado de la Orden se dispone (art. 3) que son acciones apoyables las «instalaciones eléctricas convencionales: líneas de transporte, líneas de distribución de alta, media y b aja tensión y centros de transformación, excluyéndose las instalaciones interiores, que tienen su inicio en la caja general de protección (C.G.P.) del abonado» incluyendo «la sustitución, reforma, soterramiento y cualquier otro medio técnico de modernización de las líneas y centros de trans- 
inversión. También se ignora que, por contra, con el actual régimen de propiedad inmobiliaria, al propietario del suelo se le puede convertir, a la fuerza, en sujeto pasivo de costes de urbanización que, en entre otros, sufragan los de electrificación, toda vez que un tercero no propietario, Administración pública y, ahora también, persona privada, puede iniciar el proceso de urbanización de terrenos ajenos (arts. 4.3 y 16 de la LRSV y la normativa urbanística autonómica correspondiente) con cargas a costa de los propietarios; es decir, los propietarios del suelo no tienen el monopolio de elección del mejor escenario posible para la rentabilización de unas inversiones urbanizadoras a las que se les obliga en un proceso que, incluso, puede haber iniciado un tercero sin su consentimiento y hasta con su oposición. Dicho en palabras del Tribunal Constitucional «...el art. 4 LRSV ha adoptado, en lo que ahora importa, dos criterios normativos: la sustracción del control y dirección de las actuaciones urbanisticas a los mecanismos de mercado (y por tanto a las decisiones de los propietarios o empresarios); y la participación de los particulares (propietarios o no) en la acción urbanística pública. Estas dos opciones normativas establecen, con carácter general, límites al posible juego de los derechos de propiedad (art. 33.1 CE) y -en su caso-de libre empresa (art. 38. CE) en relación con un bien escaso como es el suelo.» ${ }^{15}$.

Así las cosas, ¿qué hace suponer al Tribunal que los propietarios de terrenos que se urbanizan, pagando desde luego sus costes, no tienen el «riesgo» inherente a toda inversión privada y cuya eventual rentabilidad está en manos del mercado?, porque el argumento que esgrime el Tribunal, sólo para las empresas eléctricas, en el sentido de que la inversión se costea «independientemente de que la urbanización a la que vaya a dar nuevo servicio fructifique o no en viviendas o industrias», también es predicable de los propietarios que, con la urbanización, disponen sólo de solares cuyo precio en el mercado vendrá fijado por la demanda del producto inmobiliario que en ellos sea susceptible de construir, eso si, con más inversión en la edificación y el inherente riesgo empresarial.

Además, si los propietarios obtienen plusvalías, como dice la sentencia, «...como consecuencia del suministro de electricidad que éstas (las com-

formación existentes que contribuyan a la mejora de la calidad, regularidad y seguridad del suministro». Las ayudas tienen la consideración de subvención a fondo perdido (art. 3.2). El importe de las subvenciones puede alcanzar al 40 por 100 del coste total de la inversión y son beneficiarios de las mismas (art. 4) las corporaciones locales, empresas, comunidades de regantes, cooperativas y «compañías eléctricas» que presente proyectos de electrificación rural en municipios menores de 20.000 habitantes o que, aún rebasando tal cifra de población, estén revestidos de determinadas circunstancias singulares.

${ }^{15}$ STC 164/2001, de 11 de julio, FJ 9. 
pañías eléctricas) hacen posible» es porque aquellos han pagado y cedido gratuita y previamente las instalaciones, a lo que se ha de añadir que los usuarios pagarán los derechos de acometida y los recibos de electricidad, siendo los receptores de aquéllas y éstos las compañías eléctricas. Plusvalías urbanísticas privadas, en cualquier caso, que, por mandato constitucional, están afectas a la participación de «la comunidad» (art. $47 \mathrm{CE}$ ), lo que se manifiesta en la cesión a las Administraciones Públicas de un porcentaje del aprovechamiento urbanístico que el planeamiento atribuye a los propietarios ${ }^{16}$. Resulta inaudito que esas plusvalías, ya gravadas por el ordenamiento sobre los deberes de la propiedad inmobiliaria como se acaba de decir, puedan servir de justificación intelectual a la cesión gratuita de infraestructuras e instalaciones que se incorporan al patrimonio de las empresas privadas del sector eléctrico.

Por otro lado, el que las empresas eléctricas deben asumir los "gastos derivados del mantenimiento de las instalaciones en forma que garanticen la calidad y continuidad del suministro» es, después de cedidas las instalaciones a aquéllas por quienes las han costeado y/o ejecutado y en el actual sistema liberalizado, una obviedad que, no obstante, otros sectores económicos agradecerían escuchar de tan alta magistratura.

\footnotetext{
${ }^{16}$ En este orden de cosas, más recientemente «Los señores del suelo. A propósito de un comentario de GonZÁLEZ-BERENGUER», de Pablo Gigosos y Manuel SARAVIa, en RDUyMA n. ${ }^{\circ}$ 206, de diciembre de 2003: «Las cesiones de suelo...implican la devolución a la ciudad de la porción de suelo que le corresponde, llevando a cabo de forma material el precepto constitucional de participación pública en las plusvalias generadas por la acción urbanizadora».
} 